\title{
Rancang Bangun Sistem Informasi Pendistribusian Barang Pada PT. Akbar Nusantara Perkasa
}

\author{
Wulandari', Mohamad Arif ${ }^{2}$ \\ 1,2Universitas Budi Luhur \\ Jl. Ciledug Raya, Petukangan Utara, \\ Jakarta Selatan, Telp: 021-585 3753 Fax: 021-585 3752 \\ Email: 1Wulandari@budiluhur.ac.id, 22Ahmad.arif22@gmail.com
}

\begin{abstract}
PT. AKBAR NUSANTARA PERKASA is a company engaged in the distribution of factory machinery goods. Distribution itself is an activity of distributing goods from suppliers to customers so that their use is appropriate (type, amount, price, place and time) needed. But in terms of the distribution of goods the company still has problems in terms of data searching that requires a long time, archiving data that requires extensive space, data recording errors that occur due to human error and the presentation of unprepared reports due to long data collection. Through this research, the author in an effort to design and build a computer-based information distribution system that will create not only accurate, fast and relevant information but also can overcome the problems faced by the company. In conducting this research the supporting components in this methodology are with activity diagrams, use case diagrams, class diagrams, sequence diagrams and entity relationship diagrams. While the implementation and supporting software uses the VB.Net and MYSQL programming languages. By developing an information distribution system design of goods is expected to help and reduce problems at PT. AKBAR NUSANTARA PERKASA in goods distribution activities.
\end{abstract}

Keywords: Goods Distribution, information systems, goods, Distribution, Object Oriented

Abstrak-PT. AKBAR NUSANTARA PERKASA adalah perusahaan yang bergerak dalam pendistribusian barang mesin pabrik. Pendistribusian itu sendiri adalah suatu kegiatan menyalurkan barang dari supplier ke customer sehingga penggunaanya sesuai (jenis, jumlah, harga, tempat, dan saat) yang diperlukan. Namun dalam hal pendistribusian barang perusahaan masih mengalami kendala dalam hal pencarian data yang membutuhkan waktu lama, pengarsipan data yang membutuhkan space yang luas, kesalahan pencatatan data yang terjadi karena human error dan penyajian laporan yang tidak siap saji karena pengumpulan data yang lama. Melalui penelitian ini, penulis dalam usaha merancang dan membangun sebuah sistem informasi pendistribusi barang berbasis komputer yang akan menciptakan tidak hanya informasi yang akurat, cepat dan relevan tetapi juga dapat mengatasi masalah-masalah yang di hadapi perusahaan. Dalam melakukan penelitian ini komponen-komponen pendukung dalam metodologi ini adalah dengan adanya activity diagram, use case diagram,class diagram,sequence diagram dan entity relationship diagram. Sedangkan implementasi dan perangkat lunak yang mendukung menggunakan bahasa pemograman VB.Net dan MYSQL. Dengan dikembangkan rancangan sistem informasi pendistribusian barang diharapkan dapat membantu dan mengurangi permasalahan pada PT. AKBAR NUSANTARA PERKASA dalam kegiatan pendistribusian barang.

Kata Kunci: Distribusi Barang, sistem informasi, barang, pendistribusian, Berorientasi Obyek 


\section{PENDAHULUAN}

Ilmu pengetahuan dan teknologi (IPTEK) khususnya dalam bidang komputer sudah merupakan hal yang dikuasai dalam menghadapi tantangan zaman serta persaingan yang semakin kompetitif. Gejala-gejala dari persaingan dapat dirasakan oleh perusahaan ataupun organisasi yang bergerak diberbagai bidang baik itu jasa maupun manufaktur. Pada perusahaan distributor barang, yang harus mendistribusikan barang ke setiap customer yang sedang dikerjakan oleh perusahaan PT. AKBAR NUSANTARA PERKASA membutuhkan pengolahan data yang cepat, tepat dan akurat. Namun PT. AKBAR NUSANTARA PERKASA masih memiliki beberapa permasalahan yg dihadapi yaitu masih mengalami kendala dalam hal pencarian data yang membutuhkan waktu lama, pengarsipan data yang membutuhkan space yang luas, kesalahan pencatatan data yang terjadi karena human error dan penyajian laporan yang tidak siap saji karena pengumpulan data yang lama dikarenakan penggunaan sistem yang belum terkomputerisasi. Untuk itu penulis akan membuat suatu sistem pendistribusian barang pada PT. AKBAR NUSANTARA PERKASA.

Permasalahan yang terjadi pada PT. AKBAR NUSANTARA PERKASA yaitu :

a. Informasi yang berhubungan dengan data keluar maupun yang masuk tidak dapat disajikan tepat waktu dikarenakan lama pada saat proses pencatatan dengan mencari dokumen yang dibutuhkan terlebih dahulu.

b. Sering terjadi kesalahan atau tidak akuratnya data dalam pembuatan laporan karena human error.

c. Keterbatasan media penyimpanan sedangkan dokumen/berkas membutuhkan ruang penyimanan yang cukup banyak.

d. Memungkinan terjadinya kehilangan data dan terjadinya kerangkapan data customer sangat besar.

\section{METODOLOGI PENELITIAN} berikut :

Dalam rangka menyelesaikan penelitian ini metode yang adalah sebagai

\subsection{Metode Pengumpulan Data}

\section{a. Wawancara}

Pada kegiatan ini, diajukan pertanyaan lisan dalam usaha untuk melengkapi data-data yang akan diperoleh melalui wawancara pada bagian-bagian yang terkait dalam sistem administrasi.

b. Studi Pustaka

Penulisan dilakukan dengan mempelajari berbagai bacaan diantaranya bukubuku ilmiah dan catatan-catatan yang serta bahan-bahan pustaka lain yang ada

hubungannya dengan masalah yang akan dibahas.

c. Studi Dokumen

Studi Dokumen dilakukan dengan cara meneliti dokumen pada sistem berjalan

\subsection{Metode Analisa Data}


Menganalisa sistem yang ada, yaitu mempelajari dan mengetahui apa yang dikerjakan oleh sistem dan menspesifikasikan sistem, yaitu menentukan masukan yang digunakan, database yang ada, proses yang dilakukan dan keluaran yang dihasilkan. Alat-alat digunakan antara lain[1]-[3] :

a. Activity Diagram

Digunakan untuk proses bisnis dan aliran kerja dalam banyak kasus [4] atau memodelkan alur kerja atau workflow sebuah proses bisnis dan urutan aktifitas di dalam suatu proses.

b. Use Case Diagram

Digunakan untuk melukiskan interaksi antara sistem dengan para pemakai[5] dan menjelaskan manfaat sistem yang berjalan jika dilihat menurut pandangan orang yang berada di luar sistem atau actor.

\subsection{Metode Perancangan Sistem}

Tahap perancangan sistem adalah merancang sistem secara rinci berdasarkan hasil analisa sistem yang ada, sehingga menghasilkan model sistem baru yang diusulkan, dengan disertai rancangan database dan spesifikasi program. Alat-alat yang digunakan pada tahap perancangan ini antara lain :

a. ERD (Entity Relationship Diagram)

Merupakan alat yang dapat mempresentasikan hubungan yang terjadi antara satu atau lebih komponen sistem.

b. Sequence Diagram

Diagram yang mengambarkan alur/proses dari sistem yang dibuat.

c. Spesifikasi basis data

Digunakan untuk menjelaskan tipe data yang ada pada model konseptual.

\section{HASIL DAN PEMBAHASAN}

\subsection{Ulasan Singkat Organisasi}

PT. Akbar Nusantara Perkasa (ANP), didirikan pada tahun 1997, adalah perusahaan yang khusus memasok barangbarang seperti minyak dan gas, serta industri umum. Beberapa tahun bekerja keras dengan konsisten telah membentuk perusahaan sebagai sumber garis penuh yang dapat diandalkan dan bertanggung jawab dalam mendistribusikan suku cadang asli bagi customernya. Reputasi perusahaan didukung oleh kesadaran dalam bekerja para pekerjanya dan juga didukung oleh kinerja tepat waktu dan didukung dengan hanya sedikit penolakan dari customer. Motto PT.AKBAR NUSANTARA PERKASA adalah "Kami menyediakan produk dengan kualitas produk dan waktu", maka perusahaan mencoba untuk menjadi lebih baik dalam hal kualitas produk serta waktu pengiriman. Kualitas perusahaan adalah istilah untuk menggambarkan produk dan layanan kami telah memenuhi harapan dan kebutuhan customer[3].

\subsection{Activity Diagram}

Activity Diagram digunakan untuk menggambarkan bisnis proses yang berjalan meliputi penawaran harga, pemesanan barang, penerimaan barang, pengiriman barang dan pembuatan laporan. Salah satu activity diagram yang telah 
disebutkan adalah activity diagram penawaran harga yang ditunjukan pada Gambar 1 dan gambar 2 berikut ini:

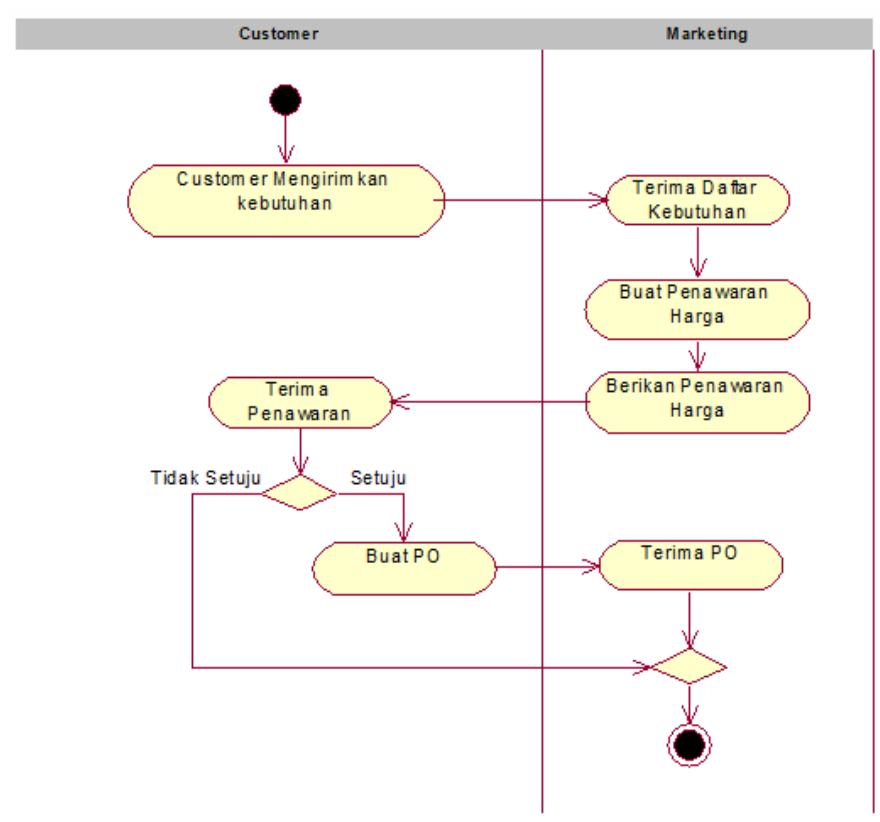

Gambar 1. Activity Diagram Proses Penawaran Harga

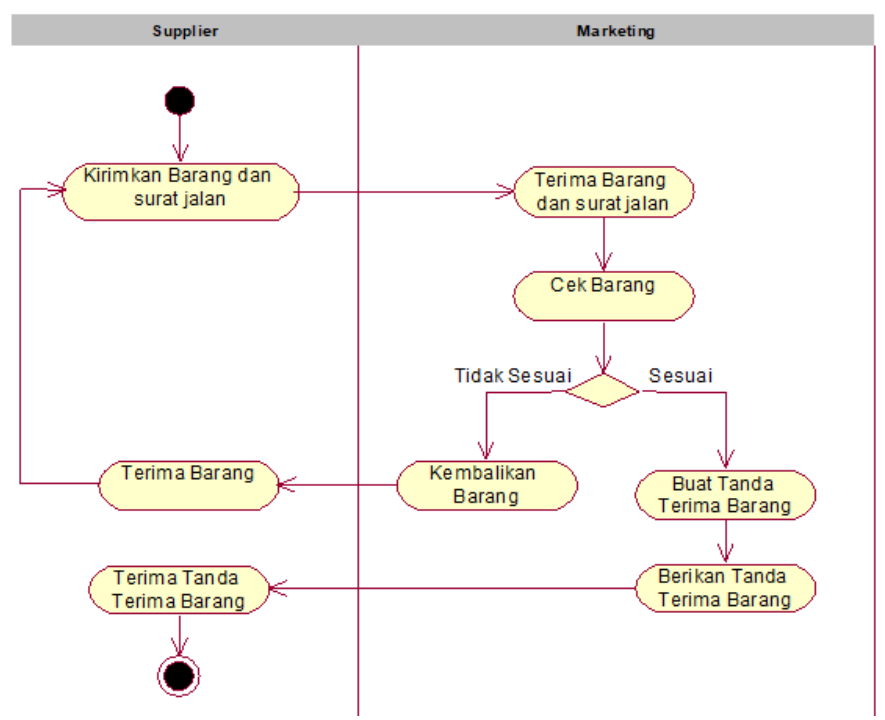

Gambar 2. Activity Diagram Proses Penawaran Harga

\subsection{Use case Diagram}

Berdasakan analisa yang dilakukan terhadap kebutuhan pengguna yang diperoleh melalui wawancara dan analisa dokumen, menghasilkan beberapa rancangan proses yang harus tersedia untuk membentuk sistem informasi pendistribusian barang yang digambarkan pada gambar 3, 4, dan 5 berikut ini: 
a. Use Case Diagram Master

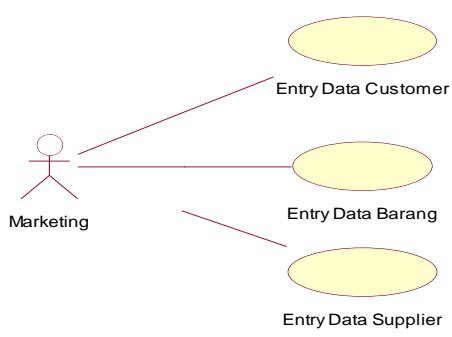

Gambar 3. Use case Diagram Master

b. Use Case Diagram Transaksi Penjualan

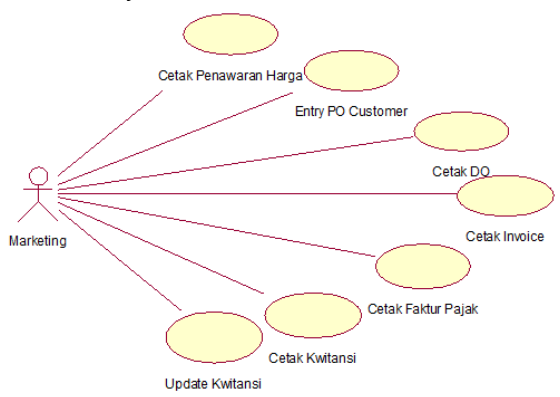

Gambar 4. Use case Diagram transaksi Penjualan

c. Use Case Diagram Transaksi Pembelian

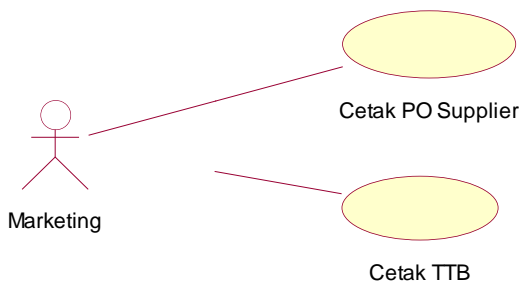

Gambar 5. Use case Diagram transaksi Pembelian

d. Use Case Diagram Laporan

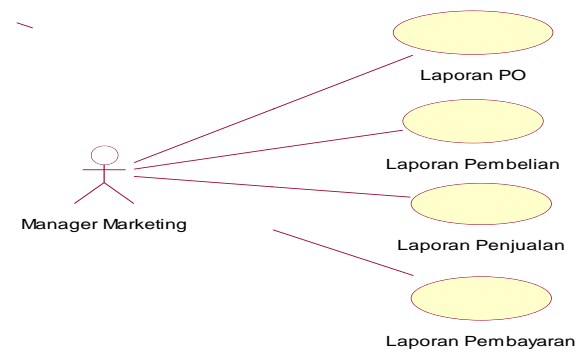

Gambar 6. Use case Diagram Laporan

\subsection{ERD (Entity Relationship Diagram}

Berdasakan analisa data untuk mendukung proses-proses yang terbentuk diatas, menghasilkan rancangan penyimpanan data dalam bentuk Entity 
Relationship Diagram seperti pada Gambar 6 dibawah yang akan dilanjutkan tahap transformasi ERD ke LRS, tahap normalisasi dan tahap spesifikasi basis data.

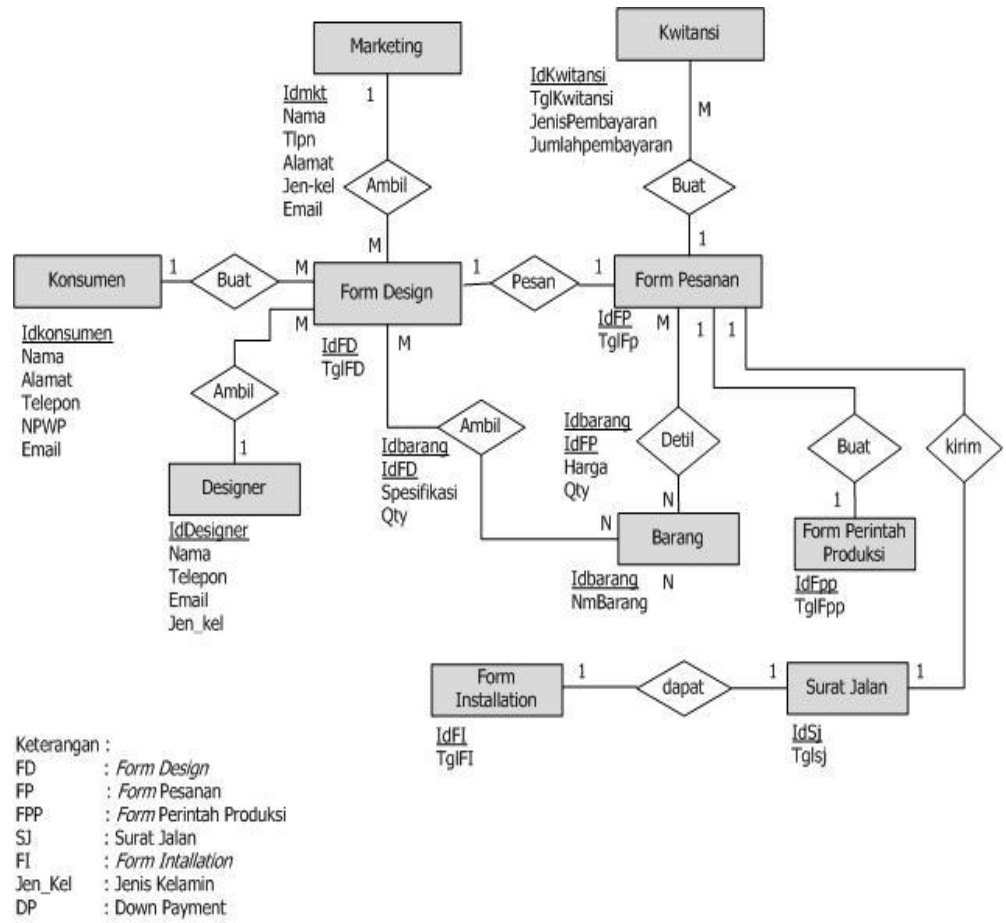

Gambar 7. ERD (Entity Relationship Diagram)

\subsection{LRS (Logical Record Structure)}

Representasi dari struktur record-record pada tabel-tabel yang terbentuk dari hasil relasi antar himpunan entitas. Menentukan kardinalitas, jumlah tabel dan Foreign Key (FK). LRS tersebut digambarkan pada gambar 7 berikut ini:

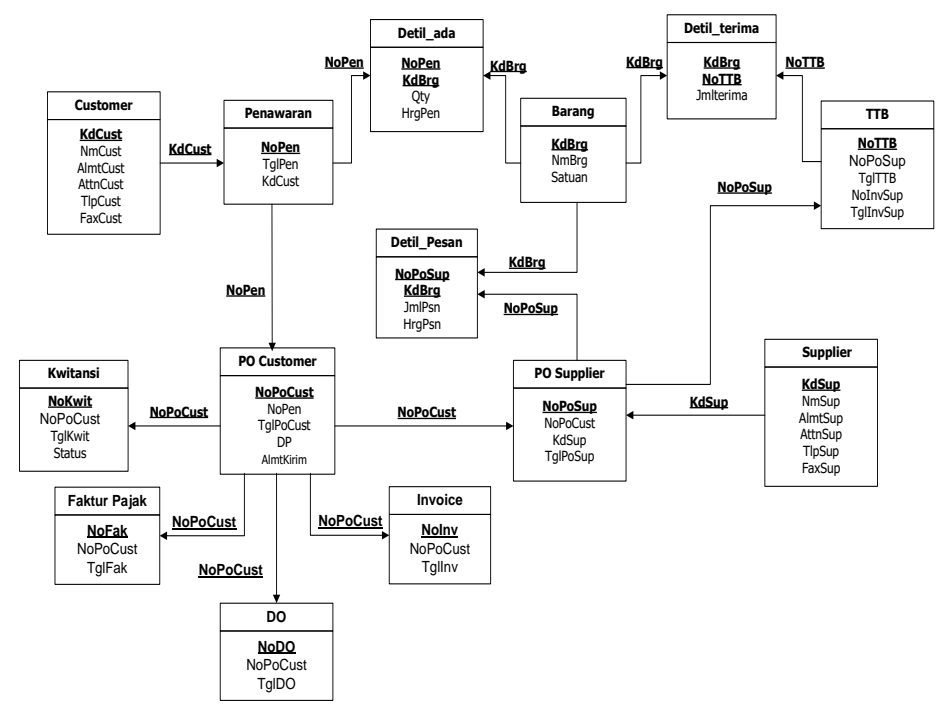

Gambar 8. LRS (Logical Record Structure)

\subsection{Spesifikasi Basis Data}

Rancang Bangun Sistem Informasi Pendistribusian Barang[Wulandari] | 206 
Spesifikasi basis data adalah rincian tiap-tiap relasi tabel atau file. Adapun Spesifikasi basis data yang diusulkan digambarkan pada tabel 1 berikut ini :

$\begin{array}{ll}\text { Nama File } & : \text { Customer } \\ \text { Media } & : \text { Harddisk } \\ \text { Isi } & : \text { Data customer } \\ \text { Organisasi } & : \text { Index Sequential } \\ \text { Primary Key } & : \text { KdCust } \\ \text { Panjang Record } & : 227 \text { Byte } \\ \text { Jumlah Record } & : 350 \text { Record }\end{array}$

Tabel 1. Tabel Spesifikasi Basis Data Customer

\begin{tabular}{|c|l|l|r|r|l|}
\hline No & Nama Field & Jenis & Lebar & Desimal & \multicolumn{1}{|c|}{ Keterangan } \\
\hline 1 & KdCust & Varchar & 4 & - & Kode Customer \\
\hline 2 & NmCust & Varchar & 50 & - & Nama Customer \\
\hline 3 & AlmtCust & Varchar & 100 & - & Alamat Customer \\
\hline 4 & AttnCust & Varchar & 50 & - & Attention \\
\hline 5 & TlpCust & Varchar & 12 & - & Telepon \\
\hline 6 & FaxCust & Varchar & 10 & - & Faximile \\
\hline
\end{tabular}

\subsection{Sequence Diagram}

Berdasarkan use case diagram dan ERD maka dibuatkan gambaran logik hubungan antara pengguna, proses dan simpanan data dalam bentuk sequence diagram yang digambarkan pada gambar $8,9,10$ berikut ini:

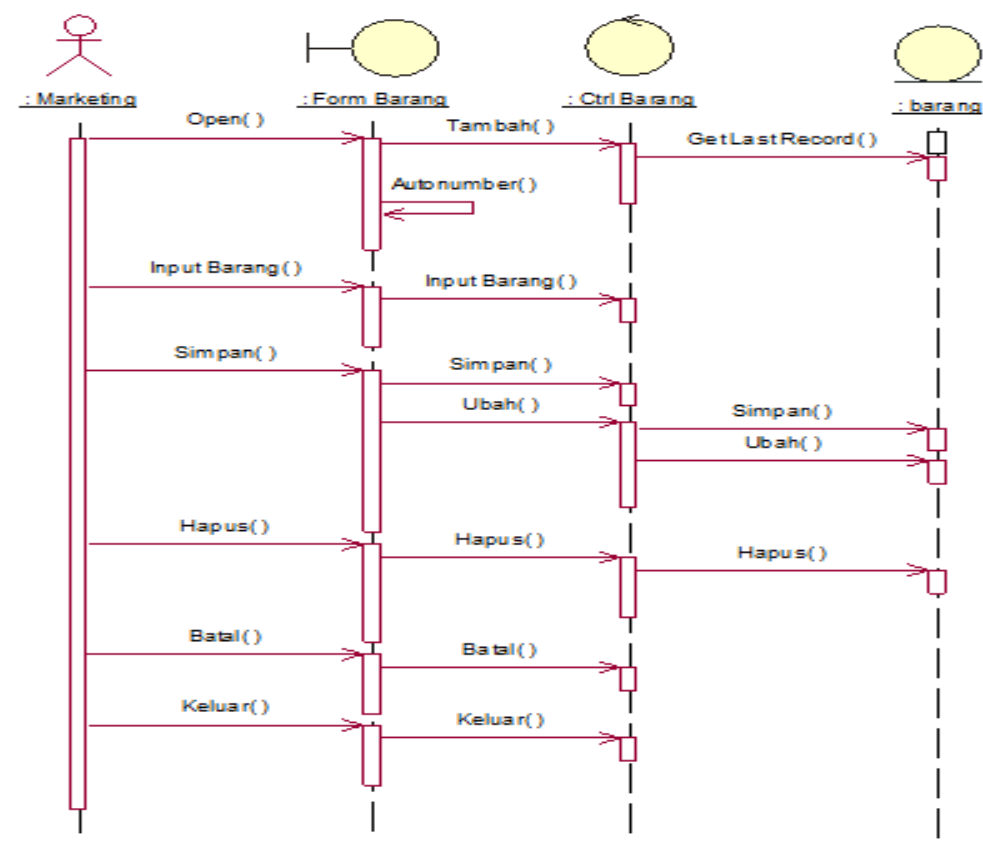

Gambar 9. Sequence Diagram Master Barang 


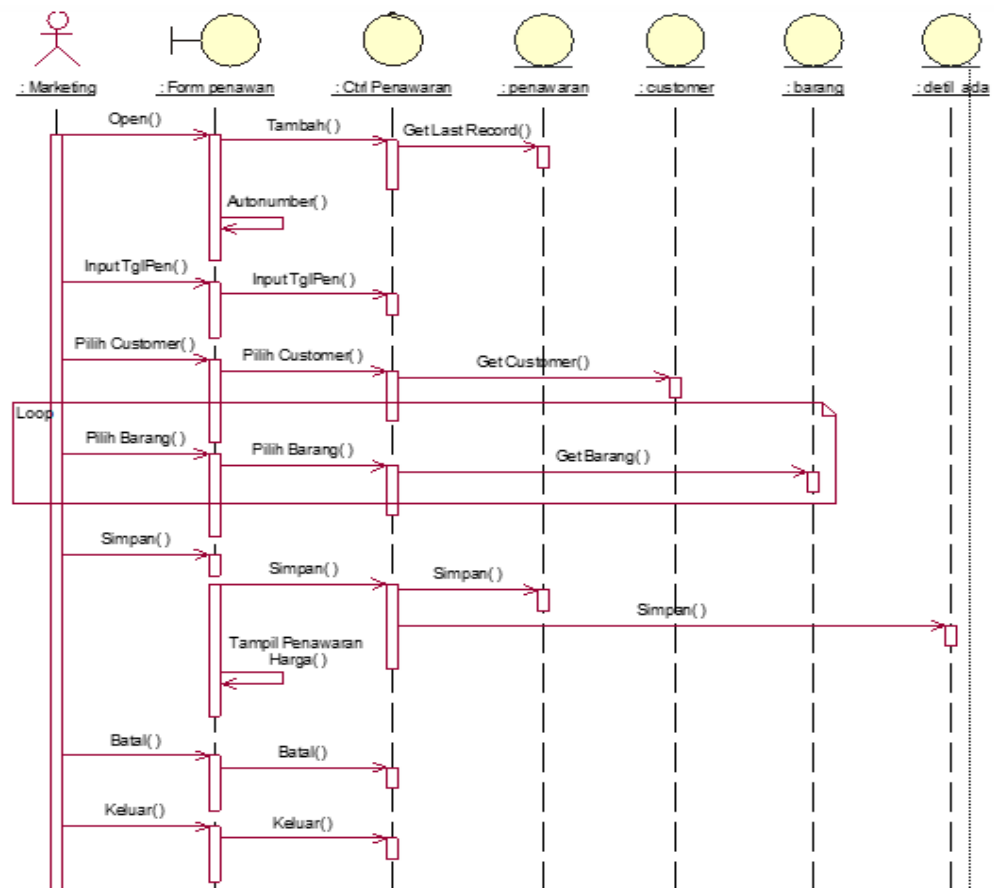

Gambar 10. Sequence Diagram Transaksi Penawaran Harga

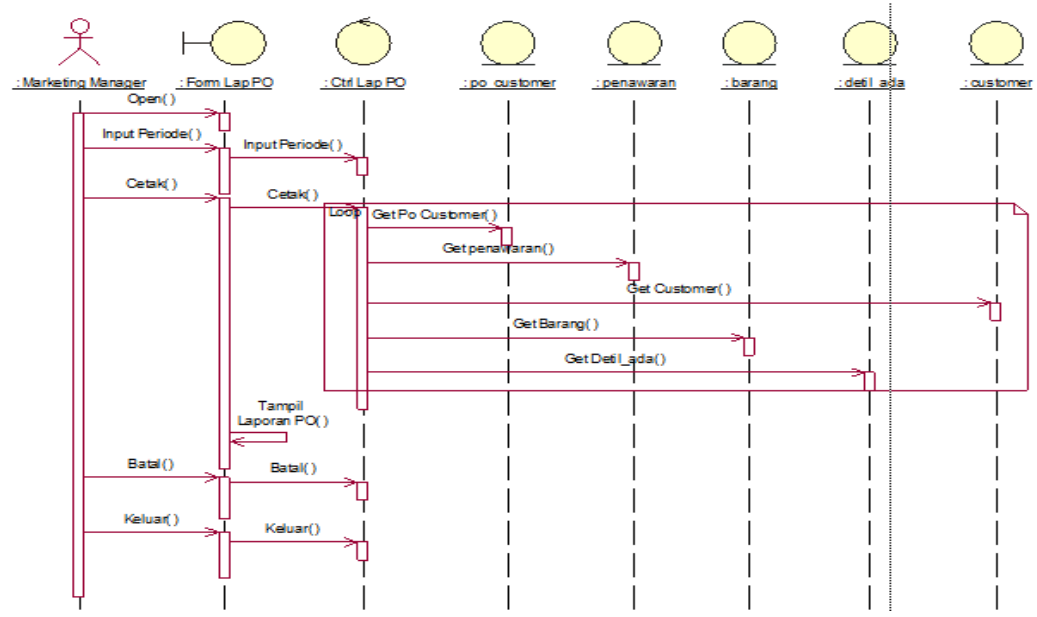

Gambar 11. Sequence Diagram Laporan PO

\subsection{Rancangan Layar}

Berdasarkan sequence diagram, kemudian dilanjutkan dengan proses rancangan layar yang ditunjukan pada gambar 11, 12, 13 dibawah ini: 


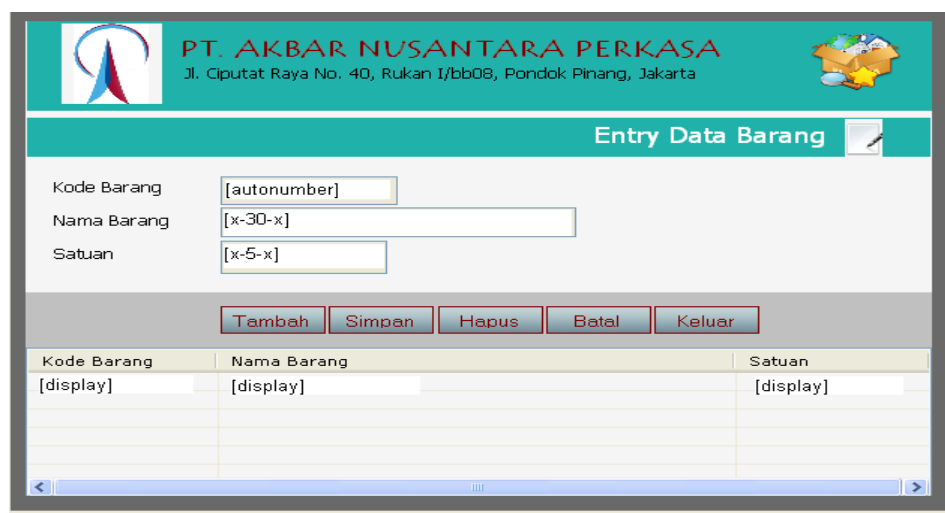

Gambar 12. Rancangan Layar Master Barang

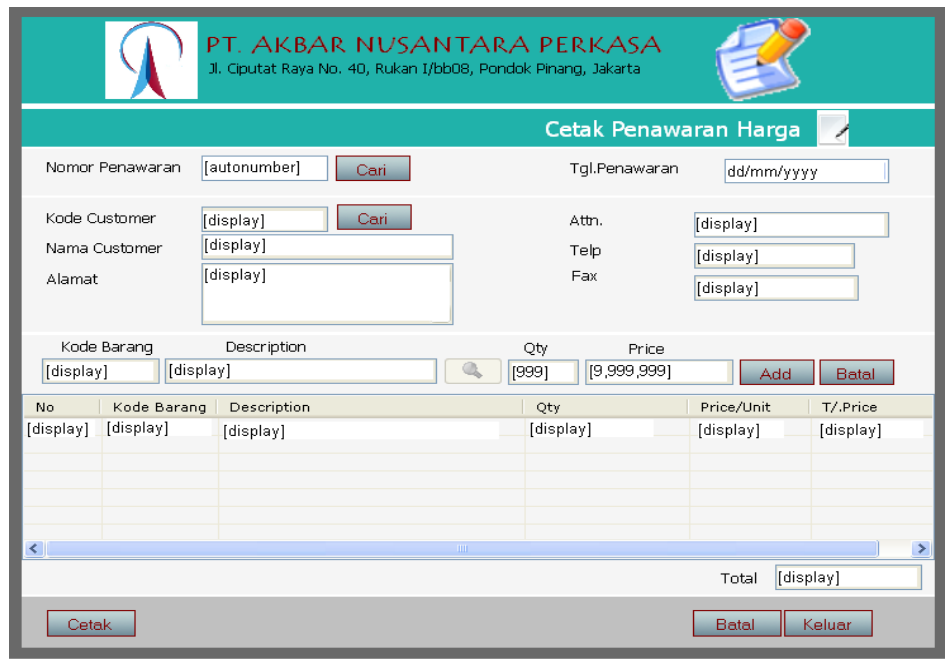

Gambar 13. Rancangan Layar Transaksi Penawaran Harga

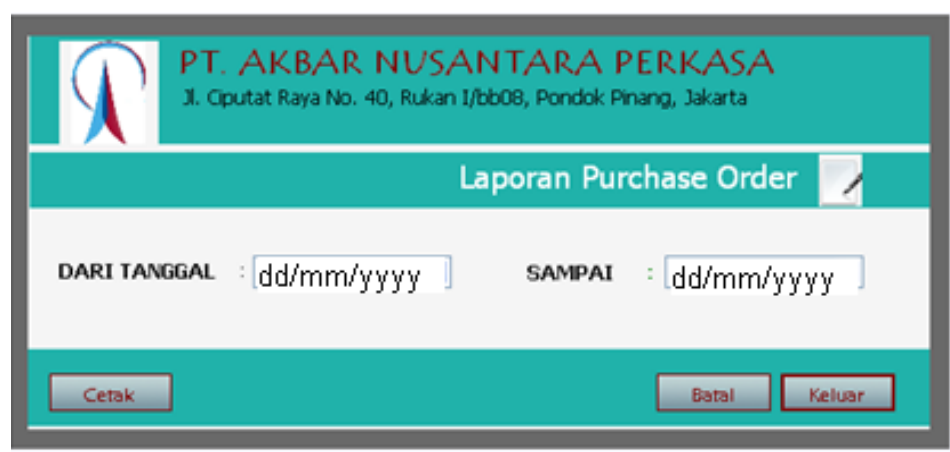

Gambar 14. Rancangan Layar Laporan PO

\section{KESIMPULAN}

\subsection{Kesimpulan}

Berdasarkan penelitian yang sudah dilakukan untuk menentukan pendistribusian barang, berikut kesimpulan yang penulis berikan :

a. Dengan adanya sistem terkomputerisasi pada PT Akbar Nusantara dalam pembuatan laporan masukan dan keluaran akan menjadi lebih mudah dan 
cepat Karena semua data dalam dokumen-dokumen tersebut sebelumnya sudah dientri dan jika dibutuhkan bisa langsung dicetak.

b. Dengan adanya sistem terkomputerisasi kesalahan karena human error dapat diminimalisir.

c. Dengan menggunakan sistem terkomputerisasi tidak lagi membutuhkan space penyimpanan yang besar.

d. Dengan adanya sistem terkomputerisasi kesalahan karena hilang dan kerangkapan data dapat dimimalisir.

Keterbatasan media penyimpanan sedangkan dokumen/berkas membutuhkan ruang penyimanan yang cukup banyak.

\subsection{Saran}

Saran-saran untuk penelitian berikutnya yaitu:

a. Perlunya dilakukan pelatihan untuk penggunaan sistem agar bagian marketing teliti dalam mengentry atau menginput data agar tingkat kesalahan data semakin rendah. Dengan demikian hasil keluaran program sesuai yang diharapkan.

b. Perlu dilakukan backup secara berkala untuk mengantisipasi kehilangan data ketika komputer rusak.

c. Diperlukan SOP untuk bagian-bagian terkait guna mengatur pola kerja sistem baru.

d. Penelitian selanjutnya dapat dikembangkan tidak hanya dalam hal pendistribusian barang.

\section{DAFTAR PUSTAKA}

[1] T. Imandasari, A. Wanto, and A. P. Windarto, "Analisis Pengambilan Keputusan Dalam Menentukan Mahasiswa PKL Menggunakan Metode PROMETHEE,” vol. 5, no. 3, pp. 234239, 2018.

[2] D. N. Batubara, A. P. Windarto, and M. R. Raharjo, "PENERAPAN PROMETHEE II PADA PEMILIHAN PRODUK CONDITIONER SEBAGAI UPAYA PENINGKATAN MINAT BELI KONSUMEN," CESS (Journal Comput. Eng. Syst. Sci., vol. 4, no. 2, pp. 191-197, 2019.

[3] Hasugian, Humisar., Wulandari., Zulkarnaen, Iqbal., 2014, Rancang bangun sistem informasi penjualan interior design dan build studi kasus: PT. Broco Mobel Industry, Konfrensi Nasional Sistem Informasi, Bali.

[4] Munawar. Pemodelan Visual dengan UML. Cetakan 1. Yogyakarta : Graha Ilmu, 2005.

[5] Akbar Nusantara Perkasa Corp, 2011, Company Profile, http://www.akbarnusantara.co.id/files/company.php. [Diakses 20 Juni 2019] 